\title{
Finite Element Analysis of Main Girder in Bridge Crane Considering Thermal-mechanical Coupling Deformation
}

\author{
Lufan Zhang ${ }^{1,3}$, Bing $\mathrm{Ma}^{2,4^{*}}$,Jun $\mathrm{Wu}^{3}, \mathrm{Hu} \mathrm{Li}^{3}$, Gangqiang $\mathrm{Li}^{3}$ \\ 1. School of Mechanical and Electrical Engineering, Henan University of Technology, Zhengzhou 450001, China \\ 2. Key Laboratory of Road Construction \& Equipment of MOE, Chang'an University, Xi'an 710064, China \\ 3. WEIHUA Group Co., Ltd., Changyuan 453400, China \\ 4.Shanxi Lu'an Antai Machinery Co., Ltd., Changzhi 046000, China \\ zzzhanglufan@163.com,m18681862425@163.com,wujun@cranewh.com,15236478711@163.com, \\ ligangqiang2007@126.com
}

\begin{abstract}
In practical application, bridge cranes are widely used to move materials. The main girder of bridge crane is prone to the deformation in high-temperature environments. In this paper, two working conditions of main girder are obtained by analyzing its deformation. The maximum deformation of main girder of 32t-22.5m singlegirder bridge crane is calculated by Finite Element Analysis (FEA) in different working conditions. The maximum deformation and stress increase linearly with the hoisting loads. Moreover, the maximum deformation and stress increase nonlinearly with the working temperature by the thermal-mechanical coupling analysis and thermal-gravity coupling analysis. Therefore, the working temperature should be taken into consider to predict of the deformation of main girder. Finally, the results of thermal-mechanical coupling analysis provide a theoretical foundation for the deformation and lightweight design of the main girder of bridge crane.
\end{abstract}

Keywords-main girder; FEA; thermal-mechanical coupling; deformation

\section{INTRODUCTION}

Bridge cranes are used widely in the mining enterprises, container terminals, construction sites, ocean exploitation, aerospace field etc. As an important bearing structure, the main girder of bridge crane is required the sufficient strength, stiffness and stability. In practical application, the main girder is prone to deformation, which is caused by bonding technology, residual internal stress, working temperature, overuse etc. The deformation of the main girder also can lead to the running resistance of bridge crane dolly increased, the gnaw rail of bridge crane dolly, cracks in the cover plate and web of the main girder [1]. Therefore, it was very important to analyze the relationship between loads and deflection. In recent years, ample researchers have been conducted on the deflection of the main girder of cranes. Considering both the influence of stiffness and rigid connected leg bending moment on main girder, ZHANG Da-peng studied the deflection of main girder in double rigid connected leg structures [2][3]. In the gantry-frame structure girder, ZHANG studied the relation between the load and the deflection on the mid-span by considering the coupling effect of the bending moments of girder and legs, the axial force and the secondary bending moments [4]. Many methods were used into study on the deflection of main girder. ZHANG studied on the prediction of the deflection of main girder of gantry crane based on the diagram multiplication method and energy method [5][6]. Considering the effects of wind load, ZHANG studied the deflection of main girder based on FEA method [7]. However, the previously mentioned methods were not taken account into the working temperature factor. In the paper, main girder is investigated by finite element method. This article is organized as follows: initially, the FEA model of main girder and its two working conditions are described. And then, finite element analyses of main girder in two cases and thermal-mechanical coupling analysis are discussed. Especially, deformation and stress of main girder are investigated. Finally, conclusions are summarized.

\section{Simulation ANALYSis}

Structure model of main girder of bridge crane was shown in Figure 1. According to the basic parameters of $32 \mathrm{t}-22.5 \mathrm{~m}$ single-girder bridge crane, the finite element model of main girder was built in ANSYS15.0 using the parametric modeling technology as shown in Figure 2. The element type is set as shell 163, and the material of main girder is Q235, and the elastic modulus is $2.06 \times 10^{5} \mathrm{MPa}$, and the Poisson ratio is 0.3 and the density is $7.85 \times 10^{3} \mathrm{~kg} / \mathrm{mm}^{3}$.

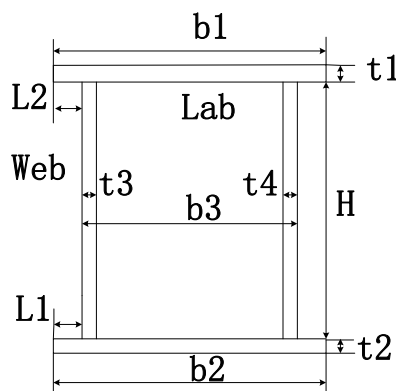

Figure 1. Structure model of main girder of bridge crane

Simulation analysis was conducted under two different working conditions:

Working condition 1: Boundary conditions were shown in Figure 3. In the Figure 3(a), when the bridge crane dolly located at the mid-span $\mathrm{C}$, force and displacement constraints are described as follows: Displacement constraints of $\mathrm{X}, \mathrm{Y}$, and $\mathrm{Z}$ directions are 
imposed at the upstream end of main girder, and displacement constraints of $\mathrm{Y}$, and $\mathrm{Z}$ directions are imposed at the downstream end of main girder. Moreover, the self-weight load, temperature load, wheel load and horizontal inertial load are imposed, respectively.

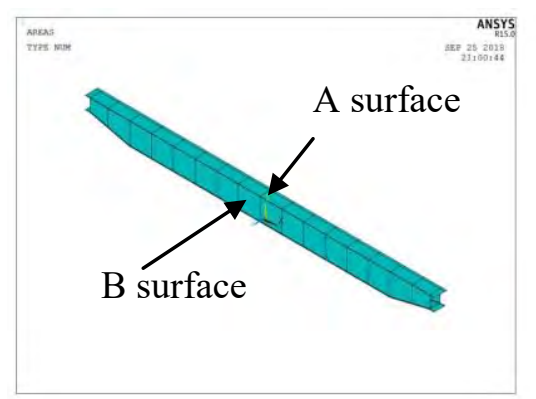

Figure 2. Finite element model of main girder

Working condition 2: In the Figure 3(b), when the bridge crane dolly located at the upstream end of main girder, the same analysis and boundary conditions are conducted. Detailed operation processes were described as follows:

Under the working condition 1 and condition 2, the hoisting loads Q are set 4t, 8t, 12t, 16t, 20t, 24t, 28t, 32t,

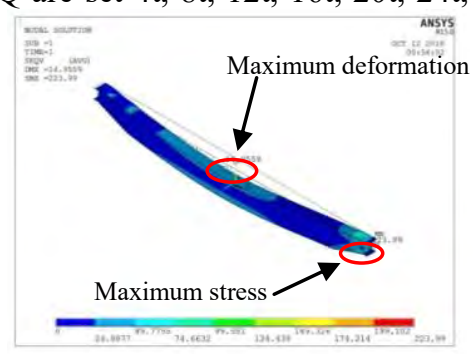

(a) Working condition 1 Figure 4. The

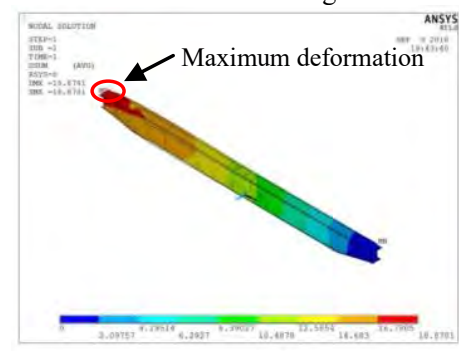

(a) The maximum deformation

Figure 5. The thermal-gravity coupling analysis under working condition 1 respectively, and the distribution of deformation and stress of main girder is obtained.

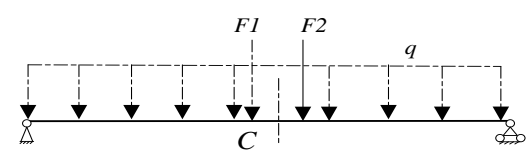

(a) Working condition 1

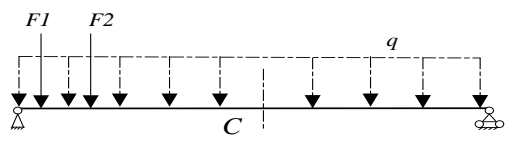

(b) Working condition 2

Figure 3. Boundary conditions

Under the working condition 1 and condition 2, firstly, the hoisting load $\mathrm{Q}$ is equal to $32 \mathrm{t}$, and then temperature is equal to $30^{\circ} \mathrm{C}, 40^{\circ} \mathrm{C}, 50^{\circ} \mathrm{C}, 60^{\circ} \mathrm{C}, 70^{\circ} \mathrm{C}, 80^{\circ} \mathrm{C}, 90^{\circ} \mathrm{C}, 100^{\circ} \mathrm{C}$ at the A surface, respectively. Temperature situation at the B surface is the same as the A surface. Moreover, temperature at the $\mathrm{A}$ and $\mathrm{B}$ surface are equal to $30^{\circ} \mathrm{C}$, $40{ }^{\circ} \mathrm{C}, 50{ }^{\circ} \mathrm{C}, 60{ }^{\circ} \mathrm{C}, 70{ }^{\circ} \mathrm{C}, 80{ }^{\circ} \mathrm{C}, 90{ }^{\circ} \mathrm{C}, 100{ }^{\circ} \mathrm{C}$, simultaneously. And the distribution of deformation and stress of main girder is obtained.

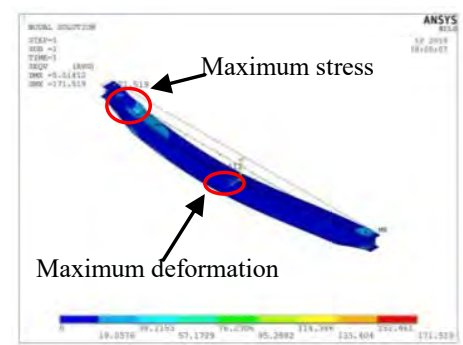

(b) Working condition 2

maximum deformation and stress by static analysis

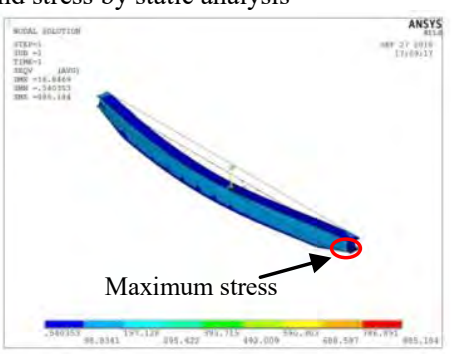

(b) The maximum stress
Simulation results were shown in Figure 4 by the static analysis under the working condition 1 and condition 2 . The deformation and stress increased gradually with the hoisting load Q. In Figure 4(a), under the working condition 1, the maximum deformation is $14.9559 \mathrm{~mm}$, and the maximum stress is $223.99 \mathrm{MPa}$. Moreover, under the working condition 2, in Figure 4(b), the maximum deformation is $5.51412 \mathrm{~mm}$, and the maximum stress is $171.519 \mathrm{MPa}$.

By the thermal-gravity coupling analysis, under working condition1, simulation results were shown in Figure 5 and Figure 6, the maximum deformation and stress were shown in
Figure 5(a) and Figure 5(b), respectively. It shows that the maximum deformation is $18.8781 \mathrm{~mm}$ at $\mathrm{T}_{\mathrm{A}}=100{ }^{\circ} \mathrm{C}$ and $\mathrm{T}_{\mathrm{B}}=100^{\circ} \mathrm{C}$, and then the maximum stress is $885.184 \mathrm{MPa}$ at $\mathrm{T}_{\mathrm{B}}=100{ }^{\circ} \mathrm{C}$. In Figure $6(\mathrm{a})$, the maximum deformation and stress are $18.3737 \mathrm{~mm}$ and $931.063 \mathrm{MPa}$ at $\mathrm{T}_{\mathrm{A}}=30{ }^{\circ} \mathrm{C}$ and $\mathrm{T}_{\mathrm{B}}=100{ }^{\circ} \mathrm{C}$ by thermal-mechanical coupling analysis under working condition 1. In Figure 6(b), the maximum deformation is $19.3743 \mathrm{~mm}$ at $\mathrm{T}_{\mathrm{A}}=100{ }^{\circ} \mathrm{C}$ and the maximum stress is 788.513 $\mathrm{MPa}$ at $\mathrm{T}_{\mathrm{B}}=100^{\circ} \mathrm{C}$ under working condition 2 . 


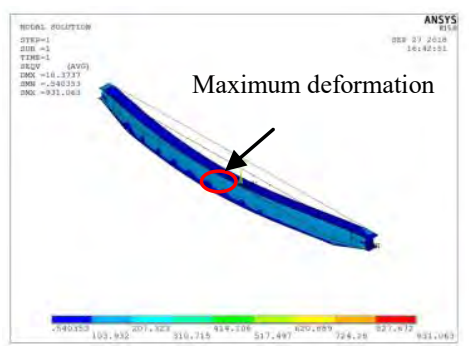

(a) working condition 1

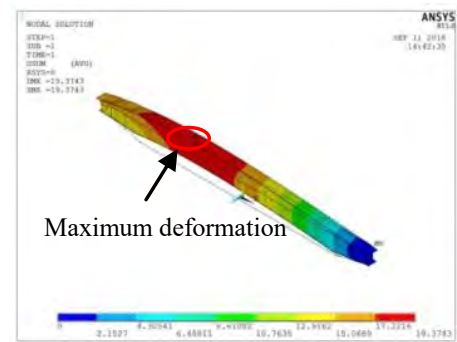

(b) working condition 2

\section{RESULTS AND DISCUSSIONS}

\section{A. Thermal-gravity Coupling Analysis}

The maximum deformation and stress were obtained by the thermal-gravity coupling analysis under the condition 1 as shown in Figure 7, Figure 8 and Figure 9, respectively. In Figure 7, the maximum deformation and stress increase nonlinearly with the temperature $\mathrm{T}_{\mathrm{A}}$. The maximum deformation $\mathrm{V}_{\max }$ decreases gradually from $9.60121 \mathrm{~mm}$ to $5.81863 \mathrm{~mm}$ at $30{ }^{\circ} \mathrm{C} \leq \mathrm{T}_{\mathrm{A}} \leq 50{ }^{\circ} \mathrm{C}$. And then the maximum deformation $\mathrm{V}_{\max }$ increases gradually from $5.81863 \mathrm{~mm}$ to $16.5478 \mathrm{~mm}$ at $50{ }^{\circ} \mathrm{C} \leq \mathrm{T}_{\mathrm{A}} \leq 100{ }^{\circ} \mathrm{C}$. The maximum stress $\sigma_{\max }$ increases gradually from $138.578 \mathrm{MPa}$ to $388.007 \mathrm{MPa}$ at $30^{\circ} \mathrm{C} \leq$ $\mathrm{T}_{\mathrm{A}} \leq 100^{\circ} \mathrm{C}$. However, the maximum deformation and stress increases linearly with the temperature $T_{B}$ in Figure 8 . The maximum deformation $\mathrm{V}_{\max }$ increases gradually from $10.0398 \mathrm{~mm}$ to $16.8469 \mathrm{~mm}$ and the maximum stress $\sigma_{\max }$ also increases gradually from $170.473 \mathrm{MPa}$ to $885.184 \mathrm{MPa}$ at $30^{\circ} \mathrm{C} \leq$ $\mathrm{T}_{\mathrm{B}} \leq 100^{\circ} \mathrm{C}$. In Figure 9, when the temperature $\mathrm{T}_{\mathrm{A}}$ is constant, the maximum deformation $\mathrm{v}_{\max }$ increases linearly at $30^{\circ} \mathrm{C} \leq \mathrm{T}_{\mathrm{B}} \leq$ $100^{\circ} \mathrm{C}$. Inversely, the maximum deformation $\mathrm{V}_{\max }$ increases gradually and the maximum stress $\sigma_{\max }$ decreases gradually as the $\Delta \mathrm{T}\left(\Delta \mathrm{T}=\mathrm{T}_{\mathrm{B}}-\mathrm{T}_{\mathrm{A}}\right)$ increases.

\section{B. Thermal-mechanical Coupling Analysis}

The maximum deformation and stress were obtained by the thermal-mechanical coupling analysis as shown from Figure 10 to Figure 15, respectively. Under the condition1, in Figure 10 and in Figure 11, the results indicate that that the maximum deformation and stress increase nonlinearly with the temperature $\mathrm{T}_{\mathrm{A}}$. Inversely, the maximum deformation $\mathrm{V}_{\max }$ increases linearly and the maximum stress $\sigma_{\max }$ increases nonlinearly with the temperature $T_{B}$. The maximum deformation $\mathrm{v}_{\max }$ firstly decreases and then increases, but the maximum stress $\sigma_{\max }$ increases all the time with the temperature $\mathrm{T}_{\mathrm{A}}$. However, the maximum stress $\sigma_{\max }$ firstly decreases and then increases, but the maximum deformation $\mathrm{V}_{\max }$ increases all the time with the temperature $\mathrm{T}_{\mathrm{B}}$. In Figure 12 , as $30{ }^{\circ} \mathrm{C} \leq \mathrm{T}_{\mathrm{A}} \leq 100{ }^{\circ} \mathrm{C}$, the maximum deformation $\mathrm{v}_{\max }$ increases nonlinearly at $30^{\circ} \mathrm{C} \leq \mathrm{T}_{\mathrm{B}} \leq 60^{\circ} \mathrm{C}$ but the maximum deformation increases linearly at $60^{\circ} \mathrm{C} \leq \mathrm{T}_{\mathrm{B}} \leq 100^{\circ} \mathrm{C}$. As $30^{\circ} \mathrm{C} \leq \mathrm{T}_{\mathrm{A}}$ $\leq 100^{\circ} \mathrm{C}$, the maximum stress $\sigma_{\max }$ firstly decreases and then increases at $40{ }^{\circ} \mathrm{C} \leq \mathrm{T}_{\mathrm{B}} \leq 100{ }^{\circ} \mathrm{C}$. In addition, the maximum deformation $\mathrm{v}_{\max }$ and the maximum stress $\sigma_{\max }$ increase gradually as the $\Delta \mathrm{T}\left(\Delta \mathrm{T}=\mathrm{T}_{\mathrm{B}}-\mathrm{T}_{\mathrm{A}}\right)$ increase. Under the working condition 2 , the maximum deformation $\mathrm{v}_{\max }$ and the maximum stress $\sigma_{\max }$ increase gradually at the similar growth rate in Figure 13 and Figure 14 with the temperature $T_{A}$ and $T_{B}$. In Figure 15 , the change rule of the maximum deformation $\mathrm{v}_{\max }$ and stress $\sigma_{\max }$ is similar to under the working condition 1. When $\mathrm{T}_{\mathrm{A}}$ is more than $70^{\circ} \mathrm{C}$, the maximum stress $\sigma_{\max }$ increases linearly under the working condition 1 and working condition 2 .

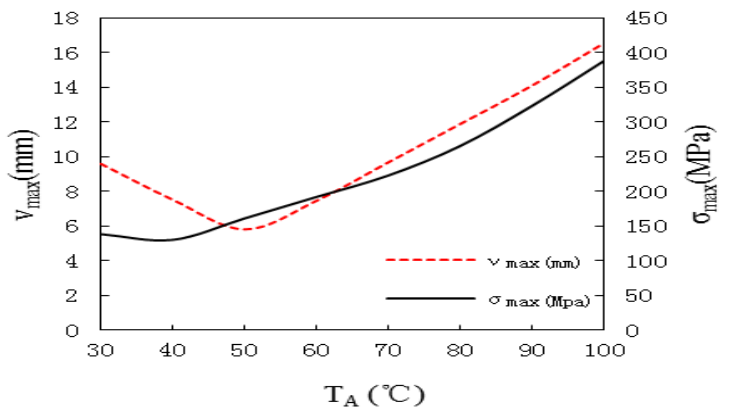

Figure 7. The maximum deformation and stress of A surface under different temperatures

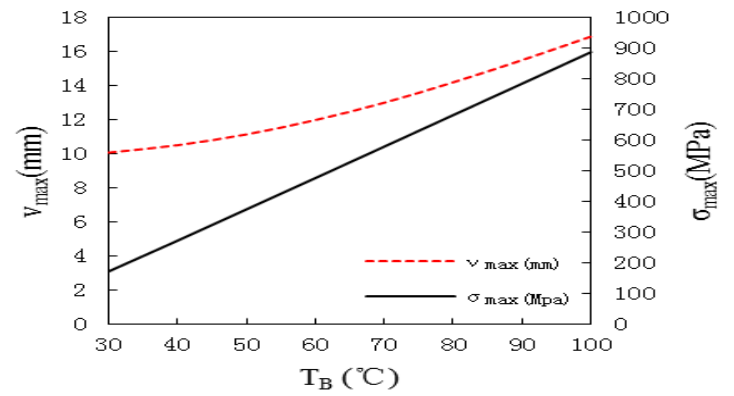

Figure 8. The maximum deformation and stress of B surface under different

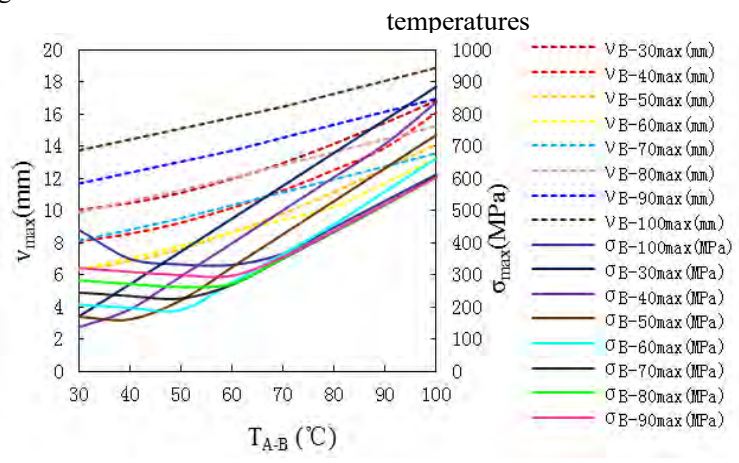

Figure 9. The maximum deformation and stress of A and B surface under different temperatures 


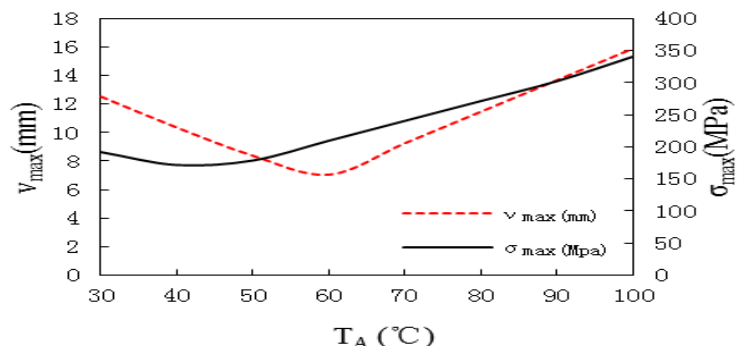

Figure 10. The maximum deformation and stress of $\mathrm{A}$ surface under working condition

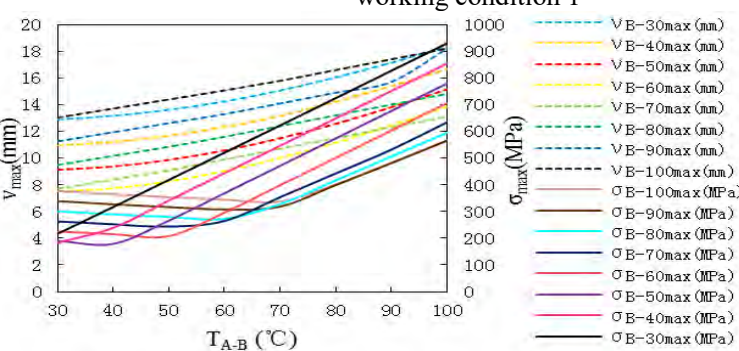

Figure 12. The maximum deformation and stress of $A$ and $B$ surface under working condition 1

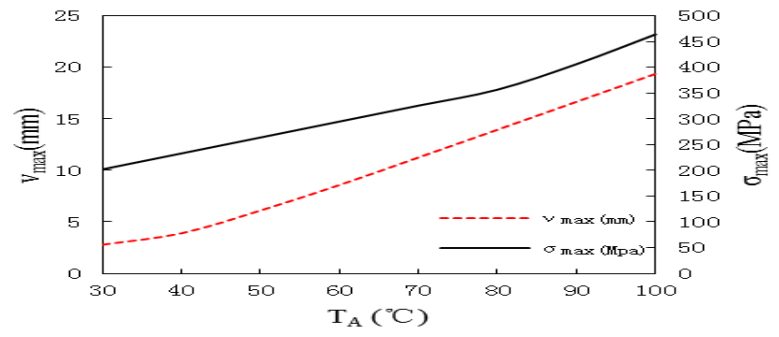

Figure 13. The maximum deformation and stress of A surface under working condition 2

\section{CONCLUSIONS}

In this paper, considering the effect of the temperature, by using a $32 \mathrm{t}-22.5 \mathrm{~m}$ single-girder bridge crane as research subject, some important conclusions are obtained as following: (1) Under working condition 1 and working condition 2, by the thermal-mechanical coupling analysis and thermal-gravity coupling analysis, it founded that the relation between the maximum deformation and stress and the temperature was not linear within certain limits. (2) In high-temperature environments, the working temperature should be taken into consider to predict of the deformation of main girder. In future, many influence factors should be considered to predict the deformation of main girder.

\section{ACKNOWLEDGMENT}

This research was financially supported by the China Postdoctoral Science Foundation, the National Natural Science Foundation of China (Grant No.51705132), the Science and Technology Department of Henan Province Natural Science Project (Grant No.172102210215) and the

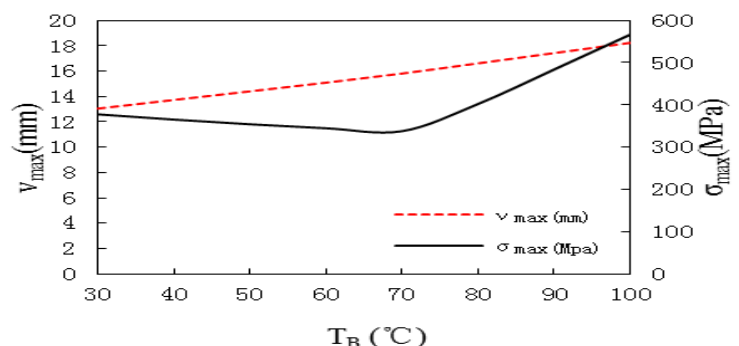

Figure 11. The maximum deformation and stress of $\mathrm{B}$ surface under working condition 1

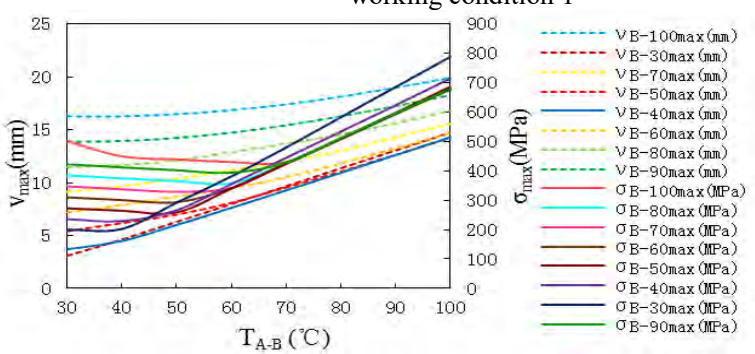

Figure 15. The maximum deformation and stress of $B$ surface under working condition 2

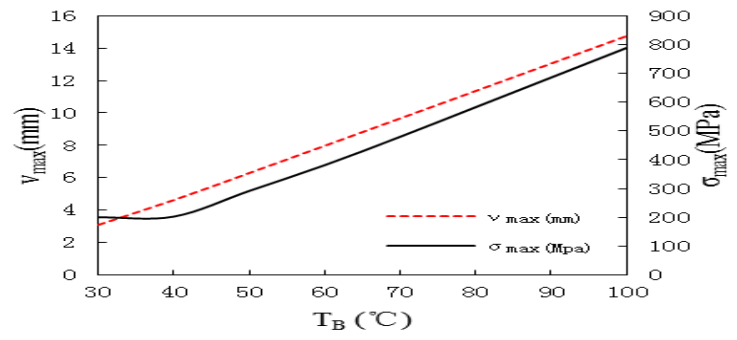

Figure 14. The maximum deformation and stress of B surface under working condition 2

Education Department of Henan Province Natural Science Project (Grant No.17A460008).

\section{REFERENCES}

[1] Hao Wen, et al. Hoisting Machinery [M]. China Machine Press, 2013.

[2] ZHANG Da-peng, et al. Influence of landing leg moment on mid-span deflection of main girder of portal crane [J]. JOURNAL OF MACHINE DESIGN, 2015, 32 (11): 31-35.

[3] Zhang Dapeng, et al. Deflection Prediction of the Girder Midspan of Large Tonnage Gantry Crane with Hinged Connection Outrigger [J] LUBRAICATION ENGINEERING, 2014, 39 (06): 99-102+10.

[4] ZHANG Da-Peng, et al. Variational analysis of mid-span deflection of gantry cranes [J]. J. Cent. South Univ. (2017) 24: 2705-2716.

[5] Zhang Dapeng, et al. Deflection Prediction for Large Tonnage Gantry Crane Girder Midspan Base on Diagram Multiplication Method[J]. Mechanical Science and Technology for Aerospace Engineering, 2015, 34 (10): 1568-1573

[6] ZHANG DaPeng, et al. Study on Prediction Deflection at Girder Midspan of Large Tonnage Rigid Connection Legs Grantry Crane Based On Energy Method [J]. Journal of Mechanical Strength,2015,37 (05): 886-891.

[7] ZHANG Yu, et al. Finite element analysis of crane girder in wind load[J]. Journal of Mechanical \& Electrical Engineering, 2013,30 (09): 1090-1092. 